\title{
Escritor sem livros: um topos pessoano para o presente
}

Sandro Ornellas ${ }^{a}$

\begin{abstract}
Resumo
$O$ artigo explora o (quase) ineditismo em livro ao longo da vida de Fernando Pessoa como um gesto extremo, mas exemplar, de recusa soberana pela escrita literária, diante da lógica de um mercado cada vez mais colonizador do nosso imaginário. A hipótese que se desenvolve ao longo do artigo é que essa recusa ou impossibilidade - pouco importa para o argumento - de Fernando Pessoa em publicar particularmente livros até o fim da sua vida, quando publica Mensagem, guarda um pensamento sobre o livro. Por outro lado, o próprio escritor também pagou em vida o preço pela radicalidade do seu gesto soberano. Essa ambivalência - tão caracteristicamente pessoana -é representada pela expressão "escritor sem livros".
\end{abstract}

Palavras-chave: Fernando Pessoa; Escrita; Livros; Soberania; Cultura literária. 
Se algum dia me suceder que, com uma vida firmemente segura, possa livremente escrever e publicar, sei que terei saudades desta vida incerta em que mal escrevo e não publico.

Fernando Pessoa, Livro do desassossego (1999, p. 190).

Em 2015, completou-se 100 anos do lançamento da Revista Orpheu, acontecimento que marcou o modernismo português. Antes, em 2009, comemorou-se o centenário do Futurismo, cujo lançamento do Manifesto por Fillipo Tommaso Marinetti, em 1909, inaugurou o ambiente entre festivo e explosivo das vanguardas modernistas. E, em 2022, comemoraremos o centenário da Semana de Arte Moderna, também de certa forma inaugural do modernismo entre nós. Pergunto a que nos servem esses e outros possíveis centenários? Não podemos considerá-los simples efemérides, numa época como a nossa, tão dada a comemorações espetacularizadas, mas ao mesmo tempo rapidamente esquecidas, afinal os modernismos históricos são um verdadeiro marco artístico-cultural em nossas sociedades e inauguram - de certo modo -, junto com a Primeira Grande Guerra, o século XX. No entanto, já não estamos tão próximos deles a ponto de nos considerarmos seus meros antagonistas ou partidários automáticos, ainda mais, se pensarmos nas reescritas da história e das memórias histórico-culturais que têm sido levadas a cabo em boa parte das sociedades contemporâneas. Se alguns discursos permaneceram, outros já mudaram bastante desde então.

É comum, aos comentadores e analistas do modernismo português, sublinhar que a revista Orpheu, nos seus dois números lançados e no terceiro abortado, não contava inicialmente com a direção de Fernando Pessoa e Mário de SáCarneiro, tendo ficado a direção do primeiro número a cargo de Luiz de Montalvôr e do brasileiro Ronald de Carvalho. Mas a dupla Pessoa e Sá-Carneiro logo teria se destacado, sendo deles a direção do segundo número, lançado, e do terceiro, somente programado. Tomo, portanto, Orpheu e sua fulminante existência enquanto forma de publicação da geração de Pessoa, assim como a ainda mais fulminante passagem pela sua direção do próprio Pessoa e de Sá-Carneiro, como pretexto para comentar o que entendo ser um topos do pensamento e obra de Fernando Pessoa e que, acho, pode nos ensinar algo sobre nosso próprio tempo. Nunca é tarde para reavaliarmos 
autores-chave, sobretudo aqueles que veem na publicação de uma revista - como Pessoa via - uma oportunidade para discutir os sentidos de sua época, para além de uma pragmática autopromoção. $\mathrm{O}$ topos do pensamento pessoano a que me refiro é o do "escritor sem livros", que aqui tratarei como um caminho para introduzir traços performáticos que rondam os gestos de escrever e publicar para Pessoa. Meu lugar aqui é o de quem está junto com várias das mistificações que ao redor de grandes autores são feitas. O nome do autor carrega consigo o imaginário das épocas em que escreveu, publicou, foi lido, esquecido e relido, o que está, sem sombra de dúvidas, presente na obra e no que circunda o nome próprio "Fernando Pessoa".

Compreende-se o ato de publicar por parte de um escritor como seu gesto público por definição, performance que lhe dá existência cultural, visibilidade social e a subjetividade que tanto anseia. A existência no campo literário, por parte do escritor, sua legitimação ante seus pares e seus leitores, tem no livro o objeto autorizado a lhe fornecer o status de autor. Fincando raízes na tradição religiosa monoteísta, que tem em livros sagrados formas singulares de encarnar o verbo e a vontade divina, o livro gutenberguiano contribuiu para dar à literatura moderna muito da sua noção de aura e autonomia, bem como ao escritor sua soberania criativa. É neste segundo item - que se desdobra do topos do "escritor sem livros" em que me detenho. Aparentemente, todavia, teríamos em Fernando Pessoa um escritor pouco ou nada soberano, dado ter publicado somente um livro em vida (desconsiderados os libretos em inglês), bem como muito pouco ter deixado concluído quando da sua morte. Para percebermos, todavia, que Pessoa pertence na verdade a uma outra estirpe de escritores, é preciso sublinhar qual concepção de soberania nos interessa.

A soberania do sujeito moderno só pode ser compreendida como uma experiência do trágico, por ser definida, segundo Georges Bataille (2012, p. 20), como um conhecimento cujo sentido não é a produção de um saber final, objetivo, útil e funcional, mas um saber provisório, frágil, instantâneo e incomunicável. Daí Bataille definir a soberania literária - e particularmente a da poesia - como "uma comunicação nos limites da incomunicabilidade", isto é, quando "a recusa de comunicar é o meio de comunicar mais hostil, mas o mais 
${ }^{1}$ Como muitas coisas na vida e obra de Pessoa, a "Empreza Íbis, Typographica e Editora" ressoa em sua própria poesia, não sendo um mero projeto profissional. Ibis também foi uma espécie de alter ego pelo qual assinava "poemas relacionados com circunstâncias familiares", bem como uma ave que gostava de imitar em ambientes familiares. Afirma Ana Maria Freitas que, pela tipografia e editora, Pessoa “[...] produz uma série de planos de sua obra e de outros autores, em versos e em prosa, em livros ou em fascículos" (2010, p. 343).

${ }^{2}$ A empresa Olisipo foi um projeto ambicioso e de caráter tanto cultural quanto comercial que não era exclusivo de Pessoa, mas envolvia outros sócios, alguns não escritores. Seu objetivo era "[...] promover a cultura e o comércio portugueses no estrangeiro e de divulgar, em Portugal, os clássicos da literatura mundial" (FREITAS, 2010, p. 559). Incluía este projeto editorial textos também do próprio Pessoa, mas a Olisipo chegou a lançar em 1922 a $2^{\mathrm{a}}$ edição das Canções, de António Botto, e em 1923 a Sodoma divinizada, de Raul Leal. Fechou nesse mesmo ano. potente" (BATAILLE, 1992, p. 56). Bataille foi contemporâneo de Pessoa, viveu entre 1899 e 1962 e teve na noção paradoxal de "sujeito soberano" um mote incansável do seu projeto. Ele parece ter perseguido intelectualmente algo cujo entendimento Fernando Pessoa exercitou à maneira de uma ética, literária e pessoal. Para um escritor se comunicar, é preciso que ele publique o que escreve, fato que pouco se deu ao longo da vida de Pessoa, diante da quantidade de inéditos e inacabados deixados, embora isso também tenha feito parte importante da sua própria literatura.

Pedro Sepúlveda, por exemplo, estudou a faceta editorialista do poeta em Os livros de Fernando Pessoa (2013) e destaca o Livro do desassossego, de Bernardo Soares-Vicente Guedes, e $O$ guardador de rebanhos, de Alberto Caeiro. O primeiro, como o projeto de um livro sem fim, o segundo, como o projeto de um livro da vida plena. O primeiro, o livro de um ajudante de guarda-livros, o segundo, o livro de um guardador de pensamentos, que "são todos sensações" (PESSOA, 2005, p. 34). Um tema ainda pouco estudado no espólio de Pessoa, segundo Sepúlveda, é a presença de um "pensamento sobre o livro", visível na enorme quantidade de projetos de livros tocados simultaneamente ao longo da sua vida, vários deles caracterizados por esboços de planos editoriais e prefácios inacabados de antologias temáticas e dos heterônimos. É certo que Pessoa sempre dialogou com os debates de sua época, mas decidir lançar-se publicamente como escritor foi algo que evitou de modo sistemático, apesar de ter tentado como editor, nos malsucedidos projetos de tipografia e editora Íbis ${ }^{1} \mathrm{e}$ na mais ambiciosa empresa Olisipo ${ }^{2}$. Lembro que sua primeira aparição no ambiente literário português foi como crítico, em 1912, e não como poeta.

Observemos um pouco a presença desse pensamento sobre livro e publicação no Livro do desassossego. Se lermos um fragmento no qual Bernardo Soares se autorretrata, dizendo "E na mesa do meu quarto sou menos reles, empregado e anónimo, escrevo palavras como a salvação da alma" (PESSOA, 1999, p. 49), a impressão é a de que Soares, ajudante de guarda-livros, não escreve para "culminar num livro" (MALLARMÉ, 2010, p. 180), pois como "reles, empregado e anónimo" já o faz profissionalmente ao preencher de notações contábeis os livros comerciais para o Moreira, o guarda-livros 
do escritório onde trabalha. Trabalhando na mesma Rua dos Douradores onde mora, Bernardo Soares passa seu dia a dia oscilando entre a escrita numérica do escritório e a escrita onírica de sua casa, a escrita diurna da profissão e a escrita noturna dos sonhos, o livro que alimenta o corpo e o livro que alimenta o espírito. Talvez não haja nada mais próximo do Livro do desassossego do que a ideia de uma escrita na fronteira entre dois mundos, entre duas necessidades: a do trabalho cotidiano e a do sonho soberano ${ }^{3}$, afinal, afirma Soares que "tudo o que é útil e exterior me sabe a frívolo e trivial ante a soberana e pura grandeza dos meus mais vivos e frequentes sonhos" (PESSOA, 1999, p. 71). Mas o dia a dia do trabalho sufoca, expropria, aliena, e Soares sabe disso:

Considerando que eu ganhava pouco, disse-me o outro dia um amigo, sócio de uma firma que é próspera por negócios com todo o Estado: 'você é explorado, Soares'. Recordou-me isso de que o sou; mas como na vida temos todos que ser explorados, pergunto se valerá menos a pena ser explorado pelo Vasques das fazendas do que pela vaidade, pela glória, pelo despeito, pela inveja ou pelo impossível. (PESSOA, 1999, p. 51)

Parece haver aí algo da ordem da recusa em publicar por parte de Soares, mas que - por isso - poderia também sugerir um discreto desejo de publicação. Pergunto assim se Soares não publica seu livro justamente porque é explorado, "como na vida temos todos que ser", ou será que publicar um livro para Soares seria tornar-se o contrário de um sujeito soberano, seria tornar-se escravo da vaidade, glória, despeito e inveja a que se refere? Pode um livro escravizar seu autor, ao invés de lhe dar soberania, como afirmei anteriormente? É ainda o próprio Soares quem responde:

O único destino nobre de um escritor que se publica é não ter uma celebridade que mereça. Mas o verdadeiro destino nobre é o do escritor que não se publica. Não digo que não escreva, porque esse não é escritor. Digo do que por natureza escreve, e

${ }^{3}$ Robert Bréchon afirma que o modelo da experiência de Bernardo Soares é a insônia e que "Antonio Tabucchi bem viu [que] a obra de Soares é uma espécie de Livro da Insônia" (1999, p. 478). por condição espiritual não oferece o que escreve. [...] Escrever é objectivar sonhos, é criar um mundo exterior para prémio [?] evidente da nossa índole de criadores. Publicar é dar esse mundo exterior aos outros; mas para quê, se o mundo exterior comum a nós e a eles é o "mundo exterior" real, o da matéria, o mundo visível e tangível? Que têm os outros com o universo que há em mim? (PESSOA, 1999, p. 215) 
Ser um "escritor sem livros", convenhamos, é uma expressão tipicamente pessoana, daquelas com que posso entender muito do seu pensamento sobre escrita, livro e publicação, desde os provocadores projetos na correspondência com Sá-Carneiro até a prioridade de uma escrita-sem-livro como forma possível de sonho ante a exploração cotidiana.

Não custa frisar que a noção de soberania desempenhava um importante papel no imaginário europeu de então, enquanto ideal buscado por um moderno espírito de sonho e superação - estética e política. Lembra-nos a crítica norte-americana Marjorie Perloff, em seu O momento futurista (1993, p. 47-8), que no período avant-guerre, entre 1909 e 1914, encontramos gestos de superação humana como as primeiras expedições bem-sucedidas aos polos norte e sul, o primeiro voo através do Canal da Mancha, o primeiro voo sobre os Alpes, a crescente comunicação à distância no uso de telefones e do telégrafo, a multiplicação de automóveis nas cidades, mas, também, o primeiro uso de aviões em uma guerra, o assassinato do arquiduque Francisco Ferdinando, herdeiro do Império Austro-Húngaro junto com o de sua esposa, a duquesa Sophie, e, no âmbito lusitano, a proclamação da República Portuguesa em 1910, após o regicídio de 19084. Desse modo, tanto cultural quanto politicamente, o sujeito do modernismo buscava estabelecer consigo, com os outros e com o mundo uma relação de conquista que trouxe tanto prodigiosas criações artísticas e técnicas quanto nefastos pesadelos políticos. Não esqueçamos que a palavra "vanguarda" tem origem militar. $\mathrm{Na}$ "Ode marítima" de Álvaro de Campos, por exemplo, flagramos essa ambígua atmosfera de sonho-e-pesadelo na famosa cena da pirataria, com sua orgia levado a cumes de gozo e assassínio, o que toda a Europa viria a experimentar em duas ferozes

${ }^{4}$ Regicídio do rei D. Carlos I e de seu príncipe herdeiro. Mas se recuarmos mais no tempo, houve uma série de outros a contecimentos ocorrendo desde o século anterior, além de marcos técnicos como o voo do 14Bis, de Santos Dumont, a construção da ferrovia Transiberiana, da Torre Eiffel e dos canais do Suez e do Panamá. guerras, na reafirmação de impérios coloniais e em genocídios totalitários: soberania e vida nua, lei e exceção, nas noções já correntes de Giorgio Agamben (2010). No caso do pensamento de Pessoa, isso pode ser percebido precisamente também pelo topos do "escritor sem livros".

A experiência do poeta como um "escritor sem livros" é sintomática desse trágico período, porque resta a ele sonhar soberanamente seus próprios livros inexistentes, fazendo do meio de comunicação por excelência da literatura moderna o livro - signo da impossibilidade do escritor em ser senhor 
do seu próprio meio e de si próprio. Sua potência em sonhar criativamente traz também sua impotência em se comunicar livremente. Já no final do século XIX, Mallarmé desenvolveu uma reflexão sobre o lugar do livro de poesia em uma sociedade avaliada a partir do cálculo numérico das páginas planas e abertas da imprensa e dos volumes dobrados que se acumulam em livrarias. Mallarmé quis dar ao discurso poético uma capacidade técnica renovada, capaz de ultrapassar o cálculo do número editorial e comercial representado pela prensa tipográfica: “O livro, expansão total da letra, deve dela tirar [da composição tipográfica], diretamente, uma mobilidade e espaçoso, por correspondência, instituir um jogo, não se sabe, que confirme a ficção" (MALLARMÉ, 2010, p. 182). O poeta se esforçou em sustentar a possibilidade de um discurso mágicopedagógico do livro de poesia no tecnicismo tipográfico, crente na imagem do "livro, instrumento espiritual". Seu famoso artigo "Quanto ao livro" forma, com o poema publicado em 1897, "Um lance de dados", bem como o apenas esboçado "O livro", um conjunto permanente de reflexão do poeta francês sobre o assunto, que parecia afligi-lo. Ele sabia que o livro de poesia nos tempos modernos se transformara em dispositivo sacrificial do próprio sujeito poético: "o redobramento virgem do livro, ainda, presta a um sacrifício pelo qual sangrou o corte vermelho dos antigos tomos, a introdução de uma arma, ou corta-papel, para estabelecer a tomada de posse" (MALLARMÉ, 2010, p. 183). Capturamos a presença desse dispositivo na prática de uma poética impessoal, no pensamento sobre o livro e no próprio inacabamento de livros, tanto em Mallarmé quanto em Fernando Pessoa.

A formulação de um pensamento sobre o livro é cuidadosamente estudada por Abel Barros Baptista em Autobibliografias (1998). O crítico elabora a tese de que sem o desenvolvimento da tipografia guthenberguiana e, consequentemente, do formato-livro como se deu a conhecer modernamente, a própria possibilidade do gênero "romance" não teria sido possível através dos grandes romancistas do século XIX. Baptista relaciona o desenvolvimento da ficção romanesca à presença de um pensamento sobre livro e publicação nos enredos romanescos de Machado de Assis, como também em Cervantes, Melville, Flaubert e Laclos, dentre outros. A antiga metáfora da natureza como um livro divino a 
ser lido e decifrado teria sido fundamental para a montagem da verossimilhança ficcional na narrativa romanesca oitocentista, bem como para a noção de autonomia textual da literatura. Não se pensaria em um romance sem pensá-lo como livro por excelência, ao mesmo tempo em que o livro do romance, enquanto "veículo", se tornaria transparente para o leitor, o que naturalizaria a narrativa romanesca como um "texto em si mesmo", eternamente idêntico a si mesmo, repetido e copiado em sucessivas impressões, que apagariam a materialidade plástica e, portanto, manipulável da forma-livro e da narrativa que ela contém.

Desde o momento em que a dimensão topográfica é encarada como suplemento aperfeiçoador da comunicação e do diálogo, da escrita e do livro, o que se reforça é ainda a noção do texto em si mesmo. [...] um texto em si mesmo correcto, que preserva uma identidade sem falhas através do tempo e através de múltiplas cópias. Ou seja, um texto em si mesmo que encontrou o veículo material que lhe permite permanecer indiferente ao veículo material, que lhe permite, em suma, permanecer texto em si mesmo. (BAPTISTA, 1998, p. 59)

O importante trabalho de Pedro Sepúlveda sobre Pessoa permitira reparar como, no início do século $\mathrm{XX}$, esse pensamento sobre o livro encontra-se em um desabrochar de crise. Para percebermos isso com mais clareza em Pessoa, eu diria que - entre o infinito Livro do desassossego e o livro da vida total do mestre Caeiro - falta, em especial, um livro que traz em seu bojo a mais importante face da soberania pessoana. Refiro-me a Mensagem, único livro que conseguiu deixar de ser projeto para se realizar e vir a público. Não comentarei o hipotético plano do livro, lançado em 1934, mas que parece ter sido gestado desde pelo menos sua estreia como crítico em 1912, com a profecia do Supra-Camões. Também não avançarei aqui sobre sua complexa estruturação, nem nas circunstâncias da pressão de amigos ou do prêmio ao qual concorreu. Interessame um sentido muito discreto de soberania ali conjugado, em meio a tantos nomes e feitos de reis, rainhas, príncipes, nobres, navegadores e mitos portugueses.

Começo olhando para a segunda seção, intitulada "Castelos", da primeira parte do livro, "Brasão". Nela, Pessoa numera seus poemas sétimo e oitavo como "Sétimo I" e "Sétimo II", para manter intacta a escolha do Brasão português 
como modelo alegórico da primeira parte do livro. No Brasão existem sete castelos desenhados. É certo que Pessoa sentiu a necessidade de colocar um poema a mais, onde deveriam ser sete, quebrando o modelo. Sem me estender, podemos afirmar que dos perfis ali interpretados literariamente, o poema dedicado a D. Dinis é o que excede a lógica da seção, pois não pertence nem às lendas peninsulares fundadoras de uma ideia de portugalidade (nos poemas "Ulisses" e "Viriato"), nem aos núcleos familiares das duas dinastias que governaram o país até 1580: os Borgonha (nos poemas "Conde D. Henriques", “D. Tareja" e "D. Afonso Henriques") e os Aviz (nos poemas “D. Pedro, o primeiro" e "D. Filipa de Lencastre"). Excede essa equação de mitos e núcleos de famílias reais, portanto, o poema "D. Diniz". Membro da Dinastia de Borgonha, foi apenas o sexto rei do país, reinando por 46 anos, o que nos leva a perguntar por que Pessoa o terá inserido em tão homogêneo grupo de pais e mães da nação. Leiamos o poema:

Na noite escreve um seu Cantar de Amigo

O plantador de naus a haver,

E ouve um silêncio múrmuro comsigo ${ }^{5}$ :

É o rumor dos pinhaes que, como um trigo

De Império, ondulam sem se poder ver.

Arroio, esse cantar, jovem e puro,

Busca o oceano por achar;

E a falla dos pinhais, marulho obscuro,

É o som presente d'esse mar futuro,

É a voz da terra anciando pelo mar.

(PESSOA, 1997, p. 22)

${ }^{5}$ Sigo a grafia utilizada na edição crítica da Coleção Archives, que por sua vez é fiel à grafia idiossincrática $(\mathrm{e}$ cheia de significações histórico-ocultistas) do poeta.
A ação de D. Dinis concentrar-se-ia na sua ligação com as letras portuguesas. Foi com D. Dinis que Portugal definiu as suas fronteiras, em 1297, fronteiras estáveis até hoje, mas também foi com ele que o latim foi substituído em atos e processos oficiais pela língua vulgar, o galaico-português, bem como foi ele quem criou a Universidade de Coimbra e incentivou os trovadores a produzirem as Cantigas de Amigo ibéricas, em contraposição à moda provençal das Cantigas de Amor. Em suma, podemos dizer que D. Dinis foi um amigo do saber, da língua e das artes. Mas restam ainda dois traços seus que são justamente os que Pessoa escolhe para cantar e incluir o rei entre o grupo de notáveis antes listados: 1) D. Dinis também 
recebeu o epíteto de "o lavrador", pois foi quem plantou na região de Leiria os pinhais que mais de 100 anos depois dariam a madeira para a construção das naus com as quais Portugal cruzaria os mares e se tornaria poderoso e lembrado Império; 2) D. Dinis foi o rei-trovador, autor de pelo menos 138 cantigas que chegariam até nossos dias. Percebemos, portanto, no poema um D. Dinis interpretado como criador do futuro Império marítimo português, "o plantador de naus a haver", Império advindo - no poema - da condição de rei-trovador, que canta, toca e anuncia como um "arroio", na "falla dos pinhais", no "som presente" e na "voz da terra", o "oceano por achar" e o "mar futuro" (grifos meus). Não é, portanto, como rei que D. Dinis é inserido na seção "Castelos" de Mensagem, mas como trovador, poeta e profeta do Império marítimo porvir. D. Dinis seria, portanto, em Mensagem o fundador das letras portuguesas, um fundador que não publicou livros, mas que muito ajudou as letras que chegariam ao início do século $\mathrm{XX}$ e ao próprio Fernando Pessoa.

Mais adiante no livro, em "Avisos", segunda seção da terceira parte, intitulada "O encoberto" e totalmente dedicada ao mito do retorno do rei D. Sebastião, Pessoa listará dois famosos intérpretes da tradição sebastianista: o sapateiro de Trancoso, Gonçalo Annes Bandarra, e o padre António Vieira. O primeiro viveu quase toda sua vida antes de D. Sebastião e escreveu um conjunto de trovas de teor messiânico que publicadas só após a morte do rei - foram imediatamente associadas a ele. A Bandarra, Pessoa nomeou no poema: "Confuso como o Universo / E plebeu como Jesus Cristo" (PESSOA, 1997, p. 75). O segundo viveu na época de formulação do sebastianismo e foi um dos seus maiores ideólogos e defensores da independência política do país, sob o domínio dos reis espanhóis até 1640. Dele Pessoa disse "[...] que teve a fama e à glória tem, / Imperador da língua portuguesa" (PESSOA, 1997, p. 76). Notemos: o primeiro é retratado no poema como "anónimo", "confuso" e "plebeu", o segundo, com "glória" e "fama", é nomeado "Imperador". Ou seja, o mais baixo e o mais alto da pirâmide social, o poder popular e o poder aristocrático. Ambos representariam para Pessoa emergências do sebastianismo ao longo da história, ligando o mito à constituição cultural, política e social do país, tanto no seu alto quanto no seu baixo escalão. Falta, todavia, citar o terceiro 
poema de "Avisos", o único dos 44 poemas do livro que não possui título, mas em que reconhecidamente Pessoa intitula a si mesmo o mais novo intérprete do sebastianismo. Nesse poema, Pessoa figura-se como poeta, pois sua autorreferência diz respeito ao próprio livro de poemas onde consta seu texto, como se lê desde seu primeiro verso, em primeira pessoa do singular: "Screvo meu livro à beira-mágoa". Sublinho que D. Sebastião nesse poema - assim como em todo o livro - é o sonho transbordante da escrita do poeta, que conclui o poema perguntando: "Ah, quando quererás voltando / Fazer minha esperança amor? / Da névoa e da saudade quando? / Quando, meu Sonho e meu Senhor?" (PESSOA, 1997, p. 77).

D. Dinis e Pessoa, portanto, são os dois únicos poetas que figuram ao lado dos demais personagens de Mensagem. É como se Pessoa apontasse que todos aqueles grandes nomes, assim como toda a nação portuguesa, nada seriam sem ter quem os colocasse sob a forma de poemas, mesmo que esses poemas jamais vissem a luz do dia sob a forma de livro. Seria engraçado pensarmos que, nesse único livro publicado, Pessoa deseja compor uma imagem de si como ponto de unidade nacional - ele, dono de uma obra tão múltipla e dispersa, seria a unidade. Por isso, voltando a Pedro Sepúlveda, destaco sua afirmação de que

as questões da publicação e do planejamento editorial de Fernando Pessoa podem ser vistas como manifestações de um problema fundamental. Esse problema é o da concepção do livro, entendido como suporte ao qual Pessoa sempre associou a ideia de um todo orgânico que seria a expressão de uma obra no seu estado de completude. Esta ideia de livro exerceu sobre todo seu trabalho de escrita uma função de ideal condutor, que corresponderia à apresentação de uma obra liberta do seu caráter lacunar, imperfeito ou fragmentário (SEPÚLVEDA, 2013, p. 40).

Temos, portanto, em Mensagem a única realização de livro como "completude" pelo poeta, exceção a confirmar a regra de uma poética caracterizada por ser "lacunar, imperfeita e fragmentária", mas que - justamente por isso - é tão fascinante e inapreensível. Parece que Pessoa desejou não concluir jamais seus livros por medo de perder a cerrada busca de um estimulante "ideal condutor" de livro. O que quero dizer é que se tornou imanente ao gesto soberano da escrita pessoana a 
incompletude a que se sujeitou pela recusa em se publicar, em tornar-se público como poeta. Quando o fez, enunciou seu ato assim: "Screvo meu livro à beira-mágoa". Até o mais soberano dos heterônimos, o mestre Caeiro, foi incapaz de evitar escrever versos que exprimem incerteza ante a publicação de seus poemas em livro, mesmo que com sua conhecida calma e simplicidade:

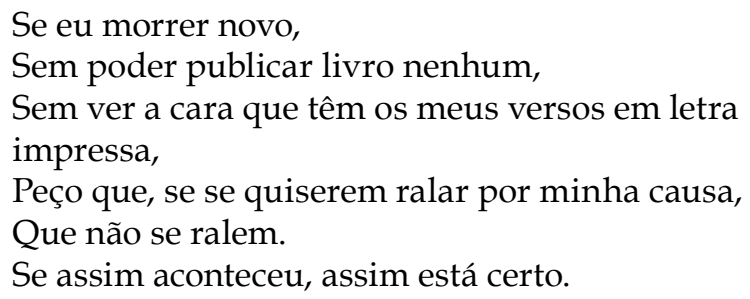

Mesmo que os meus versos nunca sejam impressos, Eles lá terão a sua beleza, se forem belos.

Mas eles não podem ser belos e ficar por imprimir, Porque as raízes podem estar debaixo da terra Mas as flores florescem ao ar livre e à vista.

Tem que ser assim por força. Nada o pode impedir. [...] (PESSOA, 2005, p. 94).

Estes versos pertencem aos Poemas inconjuntos de Caeiro e são reveladores do quanto o "descobridor da natureza" também estava exposto à incerteza trágica da vida. Para ser o sujeito da sua vida-escritura, foi preciso também submeter-se às contingências que o dobraram, impondo-lhe o contraditório e incomum desejo de imortalidade em dois momentos: 1) no retorno de certos fonemas na segunda estrofe em rimas soantes ("imprimir" e "impedir"), toantes e internas ("vErsos", "imprEssos", “bElos", "florEscem", "tErra”), e isso para um autor que disse: "escrevo a prosa dos meus versos / E fico contente" (PESSOA, 2005, p. 53); 2) quando diz que seus versos "[...] não podem ser belos e ficar por imprimir", inscrevendo o mesmo desejo por "beleza" que está no retorno do fonema / $\varepsilon$ /. Se os poemas de Caeiro querem exprimir a vida plena do seu heterônimo, se eles querem se confundir com a própria vida de seu autor, recordo que o famoso linguista russo Roman Jakobson conclui seu artigo sobre Pessoa - "Os oximoros dialéticos de Fernando Pessoa" - afirmando que "o princípio arquitetural que governa a expressão poética de Pessoa" é composto das palavras "nada", "tudo" e "metade", e que esses "três dramas" 
são no poeta "variações sobre o mesmo tema" (JAKOBSON, 2007, p. 176-7). Não é questão aqui de concordar ou discordar da análise do crítico russo, nem de sua conclusão generalizante, mas tão somente constatar que a definição da própria obra por Pessoa passa por uma visão de mundo composta por sentidos extremos e negativos, um em relação ao outro.

Por isso a permanente busca de afirmação na obra de Pessoa tem como contraponto - também permanente - a melancolia. Salta aos olhos na obra de Fernando Pessoa como - ao lado de cada sentido de soberania, cada sonho altivo, cada gesto de criação, cada livro planejado - está um afeto triste, um estado de impotência, uma sensação de ausência e um fragmento disperso. Penso nos arquifamosos versos de abertura de "Tabacaria", do heterônimo Álvaro de Campos, que diz: "Eu não sou nada. / Nunca serei nada. / Não posso querer ser nada. / A parte isso tenho em mim todos os sonhos do mundo" (PESSOA, 2010, p. 287). Bem como também nos irônicos versos da "Ode marítima", no seu mix de violenta modernidade do engenheiro futurista e de melancólico e decadente saudosismo do marinheiro português, imóvel à beira do cais. De um lado, o sonho encenado pelos furiosos piratas estripando e violentando suas vítimas e afirmando que "Não era só isto que eu queria ser - era mais do que isto, o Deus-isto!" (PESSOA, 2010, p. 118); de outro lado, a frustrante modernidade "dos sentimentos humanos, tão conviventes e burgueses, / Tão complicadamente simples, tão metafisicamente tristes! / A vida flutuante, diversa, acaba por nos educar no humano. / Pobre gente! pobre gente toda a gente!" (PESSOA, 2010, p. 131). Diria Bataille que para a conquista soberana deve o poeta submeterse à inutilidade do seu próprio dizer na modernidade, no caso de Pessoa: tornar-se um "escritor sem livros".

Comparado à cultura literária contemporânea, percebese aí uma das lições que esses centenários podem nos dar, pois o (quase) ineditismo em livro do poeta, durante sua vida, contrasta com sua múltipla criatividade. Vivemos em um tempo no qual a lógica social se confunde dia a dia com a lógica da visibilidade, comandada não por critérios estéticos ou políticos, mas mercadológicos, posto que também a estética e a política se transformaram em propaganda. A literatura hoje se mede em grande parte por critérios numéricos de cálculos que quase prescindem das intensidades e incertezas da vida. Resta-nos 
talvez a escola, atravessada pelo mercado na mesma dimensão em que já está o nosso cotidiano, estetizado pelo imaginário da publicidade. Por isso a recusa de Pessoa em publicar-se (contingente ou não, pouco importa aqui) e seu preço pago em vida são como atos de resistência ante um aparato de controle e cálculo. Pessoa representa - junto com Rimbaud e Kafka, por exemplo - um dos mais bem acabados perfis de escritor da recusa, uma família de escritores avessos ao cinismo apressado em seus gestos de autopromoção e visibilidade, mas esquecido de que, como Pessoa escreveu nos fragmentos do inacabado ensaio "Eróstrato", "o tempo depressa despacha os que o despacham com pressa" (PESSOA, 1993, p. 507-8).

Quem sabe se não foi desse fragmento que se lembrou a escritora portuguesa Maria Teresa Horta, em 2012, quando se recusou a receber o prêmio D. Dinis, das mãos do então Primeiro-Ministro de Portugal, Pedro Passos Coelho? Tal recusa gerou o cancelamento da cerimônia e pouco depois o fim do próprio prêmio - com mais de 30 anos. Com esse gesto, Teresa Horta fez da recusa à visibilidade do recebimento do prêmio junto à autoridade política sua maior potência. A inexistência da cerimônia espetacular de entrega do prêmio deu existência e visibilidade aos circuitos institucionais da vida literária que, no caso dos escritores, incluem prêmios, fotografias e edição de livros. Recusar-se a essa instância de poder, poder dizer não à publicação em livro, no caso de Pessoa, aproxima o gesto de escrever de um projeto ainda por vir, e por isso aberto ao uso comum de todos os homens. Se destacamos Pessoa, foi para sublinhar em seu pensamento sobre o livro uma discursividade capaz de suspender a força do capital pela soberana nudez da sua linguagem como puro meio. A comunicabilidade da poesia, ao ocorrer nas fronteiras da incomunicabilidade e da comunidade, passa - aparentemente - em nossos dias a ser o único gesto capaz de uma "profanação do improfanável" (cf. AGAMBEN, 2007, p. 79) fetichismo do produto-livro sob o signo sagrado do capital, uma comunicação nos limites do mercado.

\section{REFERÊNCIAS}

AGAMBEN, Giorgio. Profanações. São Paulo: Boitempo, 2007.

AGAMBEN, Giorgio. Poder soberano e vida nua: homo sacer I. 2. ed. Belo Horizonte: EDUFMG, 2010. 
BAPTISTA, Abel Barros. Autobibliografias: a solicitação do livro na ficção e na ficção de Machado de Assis. Lisboa: Relógio D'Água, 1998.

BATAILLE, Georges. A experiência interior. São Paulo: Ática, 1992. BATAILLE, Georges. La souveranaité. Paris: Ligne, 2012.

BRÉCHON, Robert. Fernando Pessoa: estranho estrangeiro. Uma biografia. Rio de Janeiro: Record, 1999.

FREITAS, Ana Maria. Íbis. In: MARTINS, Fernando Cabral (Org.). Dicionário de Fernando Pessoa e do modernismo português. São Paulo: LeYa, 2010. p. 343.

FREITAS, Ana Maria. Olisipo. In: MARTINS, Fernando Cabral (Org.). Dicionário de Fernando Pessoa e do modernismo português. São Paulo: LeYa, 2010. p. 559-560.

JAKOBSON, Roman. Os oximoros dialéticos de Fernando Pessoa. In: JAKOBSON, Roman. Linguística. Poética. Cinema. 2. ed. São Paulo: Perspectiva, 2007. p. 93-118.

MALLARMÉ, Stéphane. Quanto ao livro. In: MALLARMÉ, Stéphane. Divagações. Florianópolis: Ed. da UFSC, 2010. p. 169-185. PERLOFF, Marjorie. O momento futurista. São Paulo: EDUSP, 1993.

PESSOA. Fernando. Eróstrato. In: PESSOA, Fernando. Obra em prosa. Rio de Janeiro: Nova Aguilar, 1993. p. 473-508.

PESSOA, Fernando. Mensagem/Poemas esotéricos. Edição crítica de José Augusto Seabra (coord.). Madrid: ALLCA XX, 1997. (Col. Archives).

PESSOA, Fernando. Livro do desassossego. Edição de Richard Zenith. São Paulo: Companhia das Letras, 1999.

PESSOA. Fernando. Poesia completa de Alberto Caeiro. Edição de Fernando Cabral Martins e Richard Zenith. São Paulo: Companhia das Letras, 2005.

PESSOA. Fernando. Poesia completa de Álvaro de Campos. Edição de Teresa Rita Lopes. São Paulo: Companhia das Letras, 2010. SEPÚLVEDA. Pedro. Os livros de Fernando Pessoa. Lisboa: Ática, 2013. 


\section{Abstract \\ Writer without books: a Pessoa's topos to the present}

The article explores Fernando Pessoa's (almost) unpublished condition as to actual published books during his lifetime as an extreme, albeit exemplary, gesture of a sovereign refusal through his literary writing in face of the logic of an increasingly mindcolonizing market. The hypothesis that develops throughout the article is that Fernando Pessoa's refusal or impossibility - it's indifferent to the argument whether one or the other - to publish books in special until the end of his life, when he published Mensagem, holds a thought about books. On the other hand, the writer himself also paid - in life the price for the radicalism of his sovereign gesture. This ambivalence - so characteristically Pessoa's - is represented by the expression "writer without books".

Keywords: Fernando Pessoa; Writing; Books; Sovereignty; Literary Culture. 